\title{
Development of children's use of external reminders for hard-to-remember intentions
}

Jonathan Redshaw $^{1 *^{\ddagger}}$, Johanna Vandersee ${ }^{1 \neq}$, Adam Bulley $^{1}$ and Sam J. Gilbert ${ }^{2}$

${ }^{1}$ School of Psychology, University of Queensland, Australia.

${ }^{2}$ Institute of Cognitive Neuroscience, University College London, UK.

${ }^{\ddagger}$ Co-first authors.

*Correspondence should be addressed to:

Jonathan Redshaw. School of Psychology, University of Queensland, Australia.

j.redshaw@uq.edu.au

\section{Acknowledgements:}

SJG was supported by a Royal Society University Research Fellowship. We thank the Queensland Museum staff and patrons for their assistance with data collection. 


\begin{abstract}
The current study explored under what conditions young children would set reminders to aid their memory for delayed intentions. A computerized task requiring participants to carry out delayed intentions under varying levels of cognitive load was presented to 63 children (aged between 6.9 and 13.0 years old). Children of all ages demonstrated metacognitive predictions of their performance that were congruent with task difficulty. Only older children, however, set more reminders when they expected their future memory performance to be poorer. These results suggest that most primary school-aged children possess metacognitive knowledge about their prospective memory limits, but that only older children may be able to exercise the metacognitive control required to translate this knowledge into strategic reminder setting.
\end{abstract}




\section{Development of children's use of external reminders for hard-to-remember intentions}

Prospective memory refers to the cognitive processes that enable people to carry out specific tasks at particular future occasions (Einstein \& McDaniel, 1990; McDaniel \& Einstein, 2000; Smith \& Bayen, 2006). One may, for example, need to remember to buy milk on the way home from work, to return a book to the library next week, or to take a pill at 8am every day. To increase the chance of remembering to carry out these delayed intentions at the relevant time or location, we often set external reminders to aid our memory. Writing notes and lists, leaving items in conspicuous locations, and creating alarms on computers or smartphones are all examples of intention offloading, allowing people to improve their prospective memory performance (Gilbert, 2015a; Gilbert, 2015b). This capacity may be underpinned by a metacognitive awareness of one's cognitive limitations: once an individual knows that they may struggle to remember to carry out a task, they may choose to offload their intention to the external environment by setting up a cue to trigger future memory retrieval (Risko \& Gilbert, 2016). In other words, intention offloading can alleviate the cognitive demands associated with having to remember a delayed intention using exclusively internal processes. Although this behaviour is highly adaptive in everyday life (Hall, Johansson, \& De Léon, 2013; Harris, 1980) and potentially unique to humans (Redshaw \& Bulley, 2018), its developmental trajectory in children remains surprisingly unknown. The current study aimed to examine when children begin to utilise metacognitive evaluations of their cognitive limits to guide reminder setting.

A wide body of research shows that children can begin to pass prospective memory tasks from as early as two years onwards, with performance continuing to improve throughout childhood and adolescence (e.g., Kvavilashvili, Messer \& Ebdon, 2001; Kvavilashvili, Kyle \& Messer, 2008; Mahy, Moses \& Kliegel, 2014a, 2014b; Mattli et al., 2014; McCauley \& Levin, 2004; Redshaw, Henry, \& Suddendorf, 2016; Spiess, Meier \& 
Roebers, 2015, 2016; Zimmerman \& Meier, 2006). Kvavilashvili et al. (2001), for example, tested prospective memory performance in children aged four, five and seven years old.

Children were presented with stacks of cards showing pictures of common objects and within these stacks were several cards depicting different animals. The experimenter introduced the children to a puppet character and told them that their task was to tell the puppet what pictures were on the cards (with the premise that the puppet could not see well). Additionally, children were told that the puppet was afraid of animals, so if they saw any animal cards, they should hide them from the puppet. Results showed that prospective memory performance (remembering to hide the animal cards) increased with age, which is indicative of the broader pattern in the literature.

Previous evidence is mixed on the question of whether children's prospective memory performance can be aided by the presence of external cues. Guajardo and Best (2000) studied preschool children's performance in tasks that sometimes included reminders. For example, if the child's prospective memory instruction was to press a button whenever they saw an image of a house on the computer screen, in the external cue condition they were given a photograph of a house that they could place near the screen. As expected, 5-year old children performed better than 3-year old children. However, the external cues did not improve performance in either age group. This may have been because the cues only reminded the children of the target, and not the action they needed to perform. Kliegel and Jäger (2007), on the other hand, gave 2-6 year-old children an ongoing task that required them to name a series of pictures, except for pictures of apples that were to be placed into a box instead (the prospective memory task). Even children as young as three were more likely to place apple pictures into the box when there was an external reminder of the required action (i.e., the box was placed in front of them rather than behind them). Nevertheless, this result only demonstrates that environmental stimuli can improve children's memory for prospective 
tasks. It remains unknown whether children will choose to set their own reminders to improve future performance, and whether they will be more likely do so under conditions where their unaided performance is likely to be poorer (thus showing a capacity for strategic reminder setting). Strategic reminder setting may become increasingly important as children move through the primary school years, as they begin to take on responsibilities that require prospective memory such as routine household chores (e.g., make the bed before leaving the house) and school work (e.g., complete mathematics homework before Thursday).

Gilbert (2015a) conducted several experiments to investigate adults' use of external reminders for delayed intentions. Participants were presented with a computerised task in which they had to drag a series of numbered circles in sequence to the bottom of a box (see Figure 1). At the beginning of each trial, they were instructed that either one or three of these circles should be dragged to an alternative location (e.g. drag number 7 to the right when you reach it in the sequence). If they wished, participants could drag target circles towards their specified location at the beginning of the trial (e.g. drag number 7 next to the right side of the box at the beginning of the trial). This meant that when they eventually reached the target circle in the sequence, its location would remind them of the prospective task (analogous to leaving a library book at the front door to remind yourself to return it). Participants were told that use of this strategy was voluntary, allowing the experimenter to investigate whether participants created these external reminders by choice. Results showed that performance was better when there was just one target to remember rather than three, and that participants' performance was improved when they set external reminders. Participants set reminders on the majority of trials and, most importantly, were more likely to do so in the more difficult condition (i.e. trials with three targets). In a similar study, Gilbert (2015b) observed that participants' confidence in their unaided prospective memory capacity, independent of their objective ability level, predicted their propensity to set reminders. These findings 
demonstrate that adults are strategic in their reminder setting: they use a metacognitive evaluation of their cognitive limits to behaviourally compensate for these limits when necessary (Risko \& Gilbert, 2016). Here, we aimed to examine when children begin to engage in such strategic reminder setting.

A: Instructions

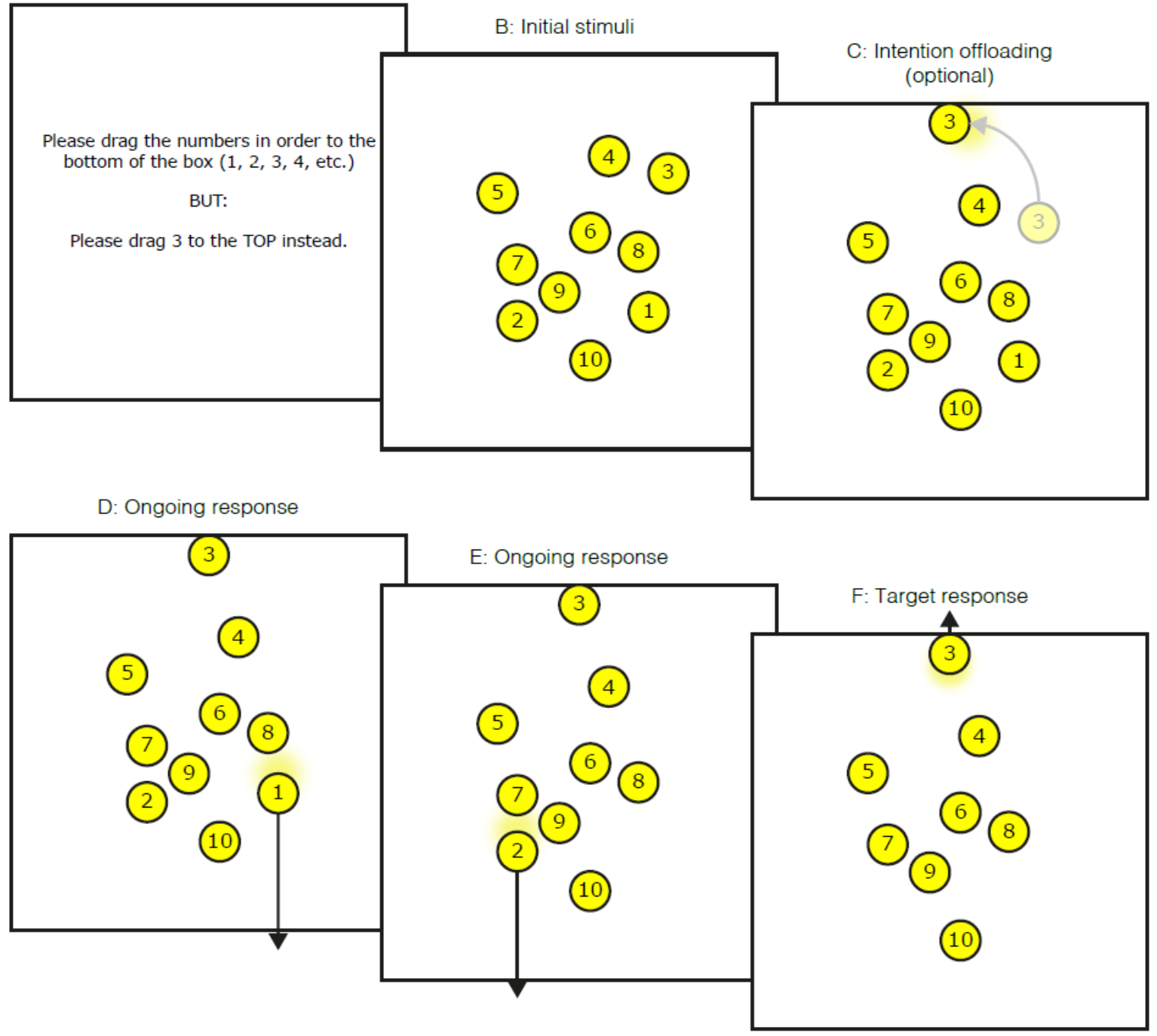

Figure 1. Schematic illustration of the intention offloading task.

There is a long history of research into the development of metacognitive knowledge in children (see Schneider \& Löffler, 2016, for a recent review). In some of the earliest work on the topic, Kreutzer, Leonard and Flavell (1975) interviewed children in kindergarten and 
grade 1, 3 and 5 about their knowledge of memory and metamemory (i.e., how certain variables such as study time and the measure of recall can affect one's performance on a memory task). They found that children of all ages had some knowledge about what makes certain memory tasks more difficult, but that older children understood more complex influences on performance, for example that retrieval of multiple items can be affected by relations between the items. Additionally, results showed that the older children were able to describe more effective strategies to improve memory. Similar age differences were found when Annevirta and Vauras (2001) tested metacognitive knowledge in a longitudinal study of children from 6 to 9 years old. They found that children's metacognitive knowledge about memory, comprehension, and learning increased and became more stable as they aged.

Nevertheless, it is important to distinguish between metacognitive knowledge (beliefs and knowledge about our own minds) and metacognitive control (use of those beliefs and knowledge to influence behaviour; Dunlosky \& Metcalfe, 2008; Flavell, 2000; Nelson \& Narens, 1990). Indeed, metacognitive knowledge of one's own cognitive capacities and limits does not necessarily translate into efficient metacognitive control of action (Nelson, 1990; Schneider, 2008). For instance, although children around 6 or 7 years of age can distinguish between easy and hard items to learn for a memory test, only around age 9 or 10 do they begin to allocate more study time to hard items than easy items (see, e.g., Dufresne \& Kobasigawa, 1989; Lockl \& Schneider, 2004; Masur, McIntyre, \& Flavell, 1973). What young children appear to lack, then, is an ability to proportionately allocate cognitive resources to tasks they have identified as particularly cognitively taxing. One might therefore expect a similar pattern in a task like Gilbert's (2015a): although young children may recognise the difference between easy-to-remember and hard-to-remember intentions, they may fail to set reminders strategically until they reach an older age.

\section{The Current Study}


We slightly modified Gilbert's (2015a) task to make it more appropriate for schoolaged children, while still maintaining the requirement to remember one or three specific intentions when dragging 10 circles to the bottom of the box. In the first phase children were not able to set reminders, whereas in the second phase this strategy was voluntary. Prior to each phase children predicted how they would perform when there were one and three targets to remember. Metacognitive knowledge of the relative difficulty of the three-target condition would be evident in cases where children predicted lower accuracy in this condition than in the one-target condition. Metacognitive control and strategic reminder setting would be evident in cases where children set more reminders when there were three targets than when there was only one.

Consistent with previous research on the development of metacognitive knowledge and metacognitive control (see Schneider, 2008, for a review), our sample included primary school children aged approximately seven through 13 years. Testing children much younger than this would have been impractical, as basic competence on the task required participants to have an understanding of left and right, as well as an ability to make metacognitive predictions on a scale ranging from 0 to 100 . Given that children begin to show some metacognitive awareness of their cognitive limitations during the preschool and early school years (Neldner, Collier-Baker, \& Nielsen, 2015; Redshaw \& Suddendorf, 2016; Schneider, 2008), we expected that even the youngest children in our sample would recognise the relative difficulty of the three-target condition. We did not have any specific predictions regarding the age at which strategic reminder setting would emerge, although it might be expected to appear around age 9 or 10 given the developmental trajectories of metacognitive control observed in other metamemory tasks (Dufresne \& Kobasigawa, 1989; Lock1 \& Schneider, 2004; Masur et al., 1973).

\section{Method}




\section{Participants}

The sample consisted of 63 children (34 males; 29 females) aged between 6.90 and 12.97 years old $(M=9.86$ years, $S D=1.70$ years $)$. Twenty one participants were aged younger than 9 years, 21 were aged between 9 and 11 years, and 21 were aged older than 11 years. All participants spoke fluent English and most were of a white middle class background. Participants were recruited through one of three methods: seven were recruited through a University of Queensland developmental psychology database; 35 were recruited at a stall at a local museum; and 21 were recruited at a local school's after-school care program. Preliminary analyses indicated that children's age did not significantly vary with testing location $\left(F(2,60)=1.4, p=.26, \eta_{p}{ }^{2}=.044\right)$; nor did any of the performance measures (overall accuracy, overall offloading rate, difference in offloading between 1- and 3-target conditions) differ according to location $\left(F(2,60)<1.7, p>.20, \eta_{p}{ }^{2}<.06\right)$. We therefore collapsed across this variable in all final analyses. Ethics approval was obtained from the University of Queensland's School of Psychology Ethics Committee and verbal and/or written consent was obtained from parents before testing.

\section{Materials}

The main intention-offloading task (see Figure 1) was presented on an iPad Air 2 and can be accessed from the following website:

“http://samgilbert.net/reminder_development/start.html”.

\section{Measures}

\section{Intention offloading task.}

Initial instruction phase. Participants were told that they would be presented with 10 yellow numbered circles inside a box and that they could move these circles around with their finger. They were told that their job was to drag the circles in order from 1-10 to the bottom of the box, making each circle disappear (the experimenter then demonstrated how to do 
this). Participants were then told that, as well as dragging each circle to the bottom of the box, they would be given specific instructions to drag one or more yellow circles to a different location in the box (either to the left, right or top of the box) instead of the bottom (see Figure 1). No specific instructions were given regarding speed of responding so there was no time pressure to respond quickly.

Phase 1. In the first phase, participants were not able to move the circles out of order. The experimenter first demonstrated how to complete the task separately with one target and three target trials and the participant practiced these trials immediately after each demonstration. Six test trials were then presented, three of which had one target, the remaining three each having three targets (in a randomised trial order). Target circles were randomly selected on each trial, with the constraint that numbers 1 and 2 were never used as targets. On three-target trials, one target was randomly assigned to each of the possible locations (top, left, and right) and instructions were always presented in numerically ascending order (i.e. possible task instructions would be "drag 4 to the left, drag 5 to the top, drag 9 to the right" or "drag 3 to the right, drag 6 to the left, drag 10 to the top"). On onetarget trials, the target location (top, left, or right) was randomly selected.

Phase 2. At the end of Phase 1, participants were informed that there would be a slight change in the next phase, in that they could now move any of the circles around the box at any time. The reminder strategy was then explained to participants. Participants were told that they could drag the target circles towards the instructed location (left, right or top of the box) at the beginning of each trial, and that when they reached this number in the sequence its location would remind them of the target instruction. The participants were told that using this strategy was entirely optional and they were again reminded of this during the practice trials. The experimenter demonstrated how to complete the task using reminders with one target, immediately followed by how to complete the task using reminders with three targets. 
The participant then practiced one trial of each condition, before six test trials were presented in the same manner as Phase 1.

\section{Metacognitive judgment scale.}

After completing the practice trials in each phase (and immediately before completing the test trials), participants were presented with a computerised scale asking them how well they thought they would perform on the task. Specifically, participants were asked how many special circles they thought they would get right, separately for trials with one target and three targets. The experimenter demonstrated that children could drag the cursor on the scale from "none of them" (left endpoint) to "all of them" (right endpoint), with a number inside the cursor ranging from $0 \%$ to $100 \%$ depending where the cursor was located on the scale.

\section{Procedure}

Participants completed the primary task as outlined above, before being thanked for their time and compensated with a small prize. Total testing time was 15-25 minutes. Some (mostly older) participants completed measures of executive function after the main task, but most children did not complete these measures due to loss of motivation or time constraints. We therefore did not include these data in the analyses.

\section{Results}

\section{Predicted and Actual Accuracy}

Predicted accuracy (as measured by the metacognitive judgement scale) was analysed with a repeated-measures ANCOVA including within-subject factors of Phase (1 vs 2$)$ and Targets (1 vs 3), along with Age as a continuous covariate allowing us to examine whether performance across conditions changed linearly as children got older. The age covariate was mean-centred so that its inclusion did not alter the evaluation of within-subject factors (Delaney \& Maxwell, 1981). As seen in Figure 2, this analysis revealed significant effects of Phase $\left(F(1,61)=8.4, p=.005, \eta_{p}{ }^{2}=.12\right)$, Targets $\left(F(1,61)=89.3, p<.001, \eta_{p}{ }^{2}=.59\right)$ and 
Age $\left(F(1,61)=8.9, p=.004, \eta_{p}{ }^{2}=.13\right)$ : children predicted better performance for phase $2(M$ $=.76, S D=.19)$ versus phase $1(M=.70, S D=.20)$, and for 1 -target $(M=.90, S D=.18)$ versus 3-target trials $(M=.56, S D=.27)$; furthermore, predicted accuracy increased with age. There were no other significant effects $\left(F(1,61)<3.5, p>.06, \eta_{p}^{2}<.055\right)$.

Actual accuracy (proportion of target circles dragged to their instructed location) was analysed in a similar manner. Again seen in Figure 2, this analysis revealed significant main effects of Phase $\left(F(1,61)=31.7, p<.001, \eta_{p}{ }^{2}=.34\right)$, Targets $\left(F(1,61)=53.1, p<.001, \eta_{p}{ }^{2}=\right.$ $.47)$, and Age $\left(F(1,61)=18.9, p<.001, \eta_{p}{ }^{2}=.24\right)$, along with an Age x Targets interaction $\left(F(1,61)=4.9, p=.031, \eta_{p}{ }^{2}=.07\right)$. Accuracy was higher in phase $2(M=.86, S D=.12)$ versus phase $1(M=.74, S D=.15)$ and for 1 -target $(M=.90, S D=.11)$ versus 3 -target trials $(M=.70, S D=.18)$. Older children were more accurate than younger children, particularly in the 3-target condition (the 1-target condition was close to ceiling), hence the Age $\mathrm{x}$ Targets interaction. There were no other significant effects $\left(F(1,61)<2.7, p>.11, \eta_{p}{ }^{2}<.042\right)$. 

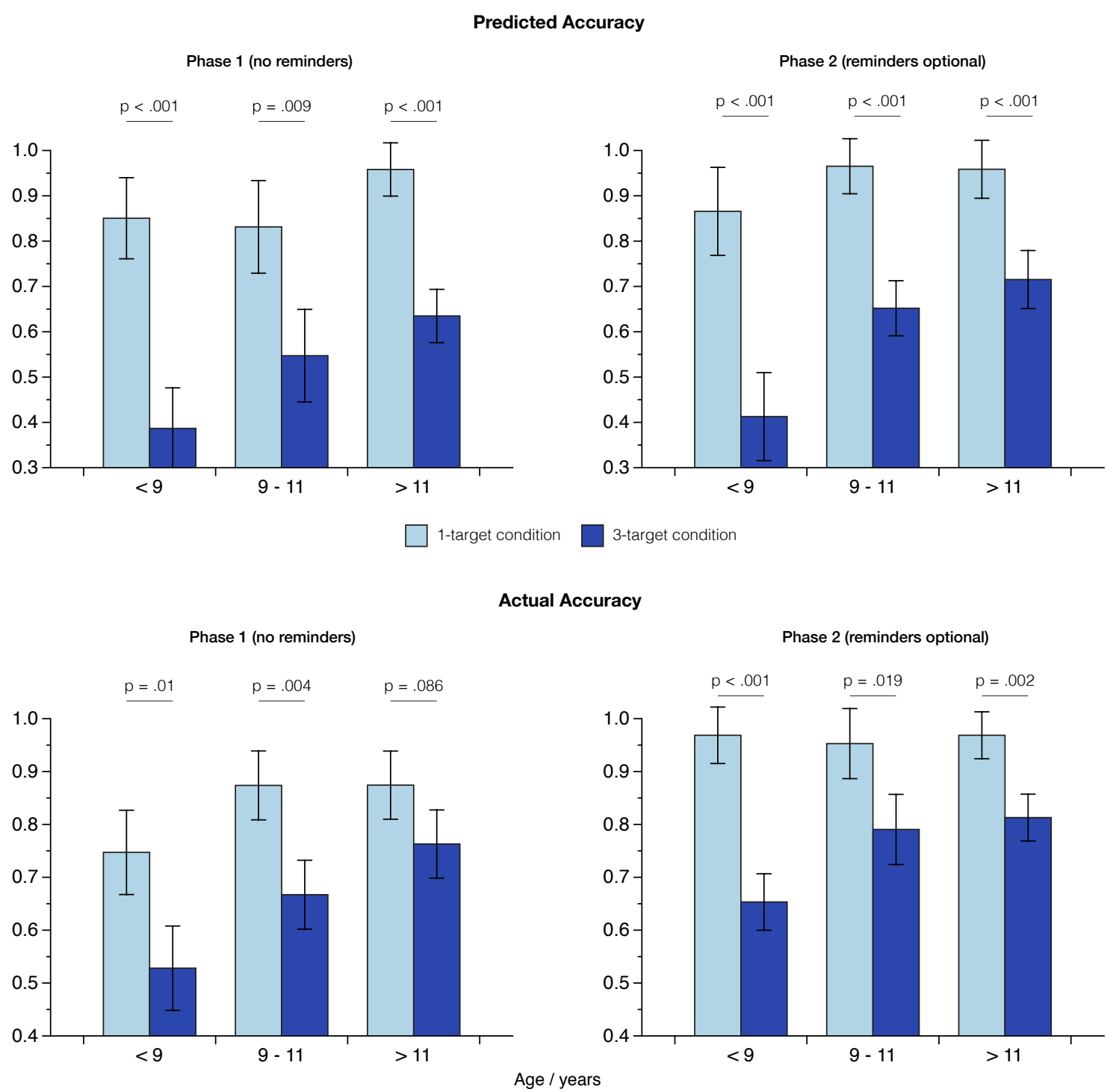

Figure 2. Predicted and actual accuracy measures in the two phases of the task. Error bars indicate 95\% confidence interval for the within-subject comparison between 1-target and 3target conditions, based on Loftus and Masson's (1994) method and scaled so that nonoverlapping error bars indicate a significant difference between means (Hollands \& Jarmasz, 2010).

Additionally, each participant's discrepancy between predicted and actual accuracy in each condition was entered into a similar analysis. This showed a main effect of Targets 
$\left(F(1,61)=14.8, p<.001, \eta_{p}{ }^{2}=.20\right)$ but no other significant effects $(F(1,61)<3.2, p>.07$, $\left.\eta_{p}{ }^{2}<.052\right)$. Children were underconfident in their predictions for 3-target trials $(M=-.14, S D$ $=.25)$ but not 1 -target trials $(M=.01, S D=.21)$. There were no significant age effects. Thus, while older children both predicted better performance and did indeed perform better (as shown in the two analyses above), the discrepancy between predicted and actual performance did not change with age $\left(F(1,61)=.21, p=.65, \eta_{p}{ }^{2}=.003\right)$. This lack of an age effect appears inconsistent with previous results suggesting that metacognitive knowledge increases during the early school years (e.g., Annevirta \& Vauras, 2001; Kreutzer et al., 1973). The children in our task, however, were able to practice the main task prior to predicting performance, which may have allowed the younger children to more accurately calibrate their predictions.

\section{Intention Offloading in Phase Two}

Offloading proportion was operationalised (as in Gilbert, 2015a; 2015b) as the difference between the proportion of target circles moved before their turn in the numerical sequence, minus the proportion of non-target circles moved before their turn. The rationale for this measure is that participants occasionally move circles before their turn in the sequence simple due to picking up the wrong circle by accident. This would not constitute offloading. By subtracting the likelihood of moving a non-target circle before its turn in the sequence $(M=.04, S D=.04)$ from the equivalent number for target circles $(M=.70, S D=$ .30) we can obtain a measure of offloading behaviour that is selectively directed towards target circles, corrected for any general tendency to accidentally select the wrong circle. This measure was entered into an ANCOVA including the within-subject factor of Targets $(1,3)$ along with Age as a continuous, mean-centred, covariate. This showed a significant effect of Targets $\left(F(1,61)=14.7, p<.001, \eta_{p}{ }^{2}=.19\right)$ : children were more likely to set reminders for 3 target $(M=.74, S D=.28)$ than 1-target trials $(M=.56, S D=.40)$. The main effect of Age was not significant $\left(F(1,61)=.2, p=.66, \eta_{p}{ }^{2}=.003\right)$ but there was a significant Targets $\mathrm{x}$ 
Age interaction $\left(F(1,61)=8.8, p=.004, \eta_{p}{ }^{2}=.13\right)$ : the tendency to set more reminders for the 3-target than 1-target trials increased with age. These findings are illustrated in Figure 3. In order to visualise the results, participants were divided into three age groups: below 9 years, 9-11 years, and older than 11 years $(N=21$ in each group). The youngest age group set a similar number of reminders in 1-target and 3-target trials $\left(F(1,20)=.005, p=.95, \eta_{p}^{2}<\right.$ $.001)$. By contrast, 9-11 year olds set significantly more reminders for 3-target trials $(F(1,20)$ $\left.=5.7, p=.027, \eta_{p}{ }^{2}=.22\right)$ and this difference in reminder setting between the two conditions was highly significant in the oldest age group $\left(F(1,20)=15.4, p<.001, \eta_{p}{ }^{2}=.43\right)$.

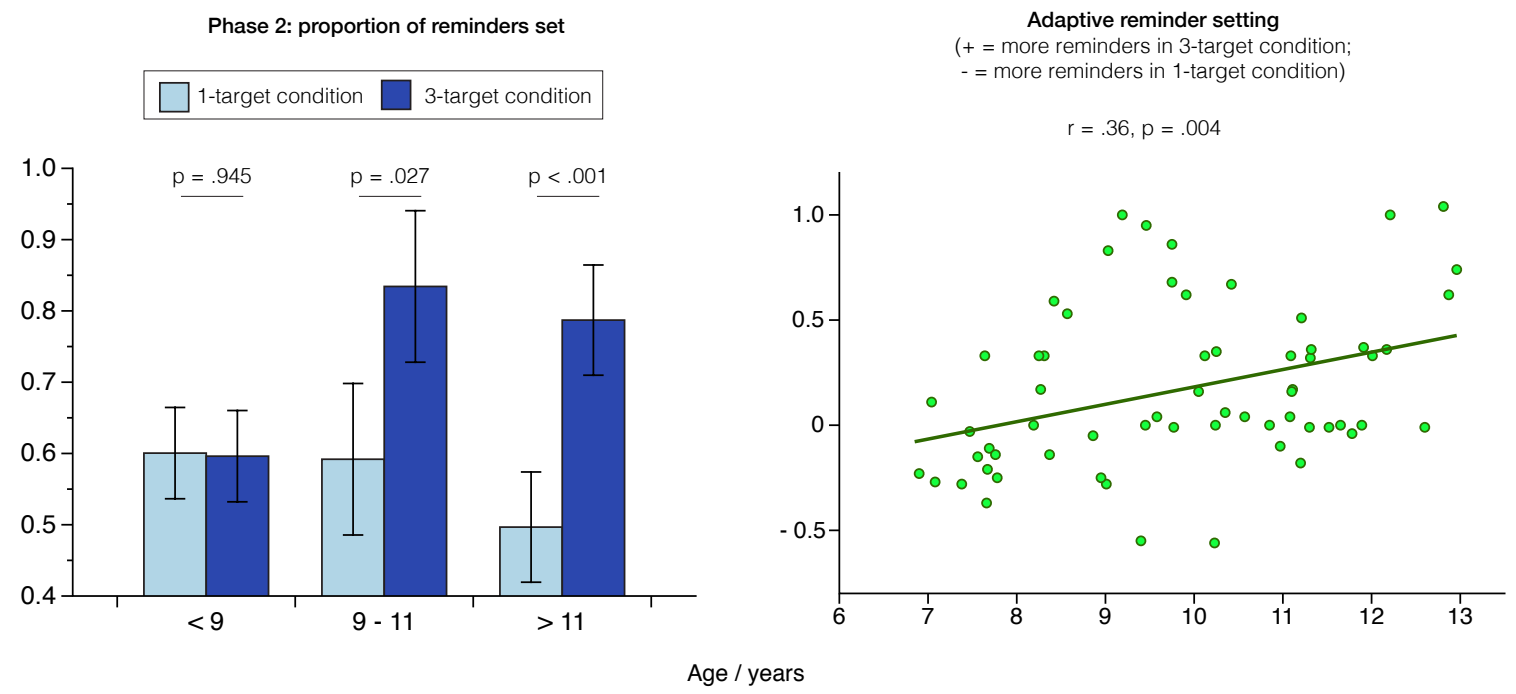

Figure 3. Use of reminders in phase 2. While younger children set a similar number of reminders for 1-target and 3-target trials, older children were much more likely to set reminders in the more demanding 3-target conditions. Error bars indicate 95\% confidence intervals for the comparison between 1-target and 3-target conditions, calculated in the same manner as Figure 2. 


\section{Metacognitive Knowledge versus Metacognitive Control}

Age did not correlate significantly with metacognitive knowledge, operationalised as the predicted difference in accuracy for 1 -target versus 3 -target trials $(r=-.19, p=.13)$. It did, however, correlate with metacognitive control, as operationalised by differential use of reminders for these conditions $(r=.36, p=.004$; Figure 2$)$. Supporting the proposed dissociation between these two measures, these two correlations are significantly different from each other $(z=2.8, p=.004$; results were similar when the knowledge measure was based on either of the phases alone, rather than collapsed across the two). The correlation between metacognitive knowledge and metacognitive control, as defined above, was not significant $(r=-.19, p=.13)$. Nor was there a significant correlation between metacognitive knowledge and task performance (i.e. the difference in accuracy between 1-target and 3target trials; $r=.07, p=.57)$. However, there was a significant negative correlation between metacognitive control and task performance $(r=-.30, p=.018)$ : a larger difference in offloading between the two conditions was associated with a smaller difference in accuracy. One interpretation of this would be that selective use of reminders for the more difficult condition helped to improve accuracy towards the level seen in the easier condition, hence reducing the difference between the two. Alternatively (or in addition), this pattern could reflect increasingly selective offloading in older children, who also had a smaller performance difference between conditions due to a ceiling effect.

\section{Discussion}

The current study was the first to investigate the development of metacognitive evaluations and use of external reminders for remembering delayed intentions. Although the present paradigm involved only a brief retention interval between encoding intentions and acting on them, results were consistent with previous research investigating prospective memory over longer intervals, showing that performance increases throughout childhood and 
degrades under high cognitive demand (Leigh \& Marcovitch, 2014; Kvavilashvili et al., 2008; Mattli et al., 2014; Ward et al., 2005; Zimmerman \& Meier, 2006). Only the older children in our sample, however, engaged in strategic reminder setting in that they set more reminders under conditions of high demand. There are several possible explanations for this observed developmental trajectory.

A first possibility is that the younger children did not set more reminders in threetarget trials simply because they were less willing to change strategies after completing the task without reminder setting in phase one. This explanation can be ruled out, however, by noting that the overall proportion of reminders set did not vary with age, and that even the younger children set reminders for more than half of the targets (see Figure 3). It is unlikely that they would do this if they were unwilling to change strategies between phases.

A second potential explanation is that the younger children were overconfident in their abilities (especially in the three target condition) and, therefore, did not think that reminders would be useful to them. Inconsistent with this interpretation, however, the metacognitive judgement scores revealed that younger children were actually less confident than older children when predicting their performance; and children across all ages were appropriately more confident in the one target trials than in the three target trials. There was no significant influence of age on the discrepancy between predicted and actual performance. Thus, consistent with broader metacognition literature (e.g., Balcomb \& Gerken, 2008; Neldner et al., 2015; Redshaw \& Suddendorf, 2016), even the youngest children in our sample appeared to possess insight into the relative difficulty of the three-target trials. These results converge with those of Kvavilashvili and Ford (2014), who found that children as young as five can be highly accurate in their metacognitive knowledge of prospective memory abilities, despite showing overconfidence when asked about retrospective memory. 
One remaining explanation for the results is that the younger children, unlike the older children, lacked sufficient metacognitive control to translate their metacognitive insight into increased reminder setting in the three-target condition (see Balcomb \& Gerken, 2008; Dunlosky \& Connor, 1997; Nelson \& Narens, 1990; Schneider, 2008). Both younger and older children in our sample were aware of the relative difficulty of the three-target condition (as indicated by their metacognitive evaluations), suggesting they possessed similar metacognitive knowledge of their cognitive limitations. Only older children, however, utilized these evaluations to inform strategic behaviour, such that they flexibly chose an appropriate strategy based on the cognitive demand of each trial. This interpretation is consistent with a wide body of literature on the development of metamemory, which indicates that only around age 9 or 10 do children begin to translate their well-established knowledge of memory limitations into efficient memorization behaviour (e.g., Dufresne \& Kobasigawa, 1989; Lockl \& Schneider, 2004; Masur et al., 1973). One implication of the developmental lag between metacognitive knowledge and metacognitive control is that simply making young primary-school-age children aware of cognitive limitations cannot be assumed to lead to the use of compensatory strategies (see Cherkaoui and Gilbert, 2017, for a related finding in individuals with autism spectrum conditions).

The capacity to translate metacognitive evaluations of one's cognitive limits into strategic action underpins many complex human behaviors, from recording information that is likely to be forgotten, to setting up contingency plans just in case the future does not turn out as one expects. The present findings point to a period of emergence for one instantiation of this important capacity during the early school years. 


\section{References}

Annevirta, T., \& Vauras, M. (2001). Metacognitive knowledge in primary grades: A longitudinal study. European Journal of Psychology of Education, 16, 257-282.

Balcomb, F. K., \& Gerken, L. (2008). Three-year-old children can access their own memory to guide responses on a visual matching task. Developmental Science, 11, 750-760. doi: $10.1111 / \mathrm{j} .1467-7687.2008 .00725 . \mathrm{x}$

Cherkaoui, M., \& Gilbert, S.J. (2017). Strategic use of reminders in an 'intention offloading task': Do individuals with autism spectrum conditions compensate for memory difficulties? Neuropsychologia, 97, 140-151. doi:

10.1016/j.neuropsychologia.2017.02.008

Delaney, H.D., \& Maxwell, S.E. (1981). On using analysis of covariance in repeated measures designs. Multivariate Behavioral Research, 16, 105-123. doi: 10.1207/s15327906mbr1601_6

Dufresne, A., \& Kobasigawa, A. (1989). Children's spontaneous allocation of study time: Differential and sufficient aspects. Journal of Experimental Child Psychology, 47, 274-296. doi: 10.1016/0022-0965(89)90033-7

Dunlosky, J., \& Connor, L. T. (1997). Age differences in the allocation of study time account for age differences in memory performance. Memory \& Cognition, 25, 691-700. doi: $10.3758 / \mathrm{BF} 03211311$

Dunlosky, J., \& Metcalfe, J. (2008). Metacognition. Thousand Oaks, CA: SAGE.

Einstein, G. O., \& McDaniel, M. A. (1990). Normal aging and prospective memory. Journal of Experimental Psychology: Learning, Memory, and Cognition, 16, 717-726. doi: $10.1037 / 0278-7393.16 .4 .717$

Flavell, J.H. (2000). Development of children's knowledge about the mental world. International Journal of Behavioral Development, 24, 15-23. doi: 


\section{$10.1080 / 016502500383421$}

Gilbert, S. J. (2015a). Strategic offloading of delayed intentions into the external environment. The Quarterly Journal of Experimental Psychology, 68, 971-992. doi: $10.1080 / 17470218.2014 .972963$

Gilbert, S. J. (2015b). Strategic use of reminders: Influence of both domain-general and taskspecific metacognitive confidence, independent of objective memory ability. Consciousness and Cognition, 33, 245-260. doi: 10.1016/j.concog.2015.01.006

Guajardo, N. R., \& Best, D. L. (2000). Do preschoolers remember what to do? Incentive and external cues in prospective memory. Cognitive Development, 15, 75-97. doi: $10.1016 / \mathrm{S} 0885-2014(00) 00016-2$

Hall L., Johansson P., de Léon D. (2013). Recomposing the will: Distributed motivation and computer mediated extrospection. In: A. Clark A., J. Kiverstein, \& T. Vierkant (Eds.), Decomposing the will (pp. 298-324). Oxford: Oxford University Press.

Harris, J. E. (1980). Memory aids people use: Two interview studies. Memory \& Cognition, 8, 31-38. doi: 10.3758/BF03197549

Hollands, J. G., \& Jamasz, J. (2010). Revisiting confidence intervals for repeated measures designs. Psychonomic Bulletin \& Review, 17, 135-138. doi: 10.3758/PBR.17.1.135

Kliegel, M., \& Jäger, T. (2007). The effects of age and cue-action reminders on event-based prospective memory performance in preschoolers. Cognitive Development, 22, 33-46. doi: 10.1016/j.cogdev.2006.08.003

Kreutzer, M. A., Leonard, C., Flavell, J. H., \& Hagen, J. W. (1975). An interview study of children's knowledge about memory. Monographs of the Society for Research in Child Development, 40, 1-60. doi: 10.2307/1165955

Kvavilashbili, L., \& Ford, R. M. (2014). Metamemory prediction accuracy for simple prospective and retrospective memory tasks in 5-year-old children. Journal of 
Experimental Child Psychology, 127, 65-81. doi: 10.0.3.248/j.jecp.2014.01.014

Kvavilashvili, L., Messer, D. J., \& Ebdon, P. (2001). Prospective memory in children: The effects of age and task interruption. Developmental Psychology, 37, 418-430. doi: $10.1037 / 0012-1649.37 .3 .418$

Kvavilashvili, L., Kyle, F., \& Messer, D. (2008). The development of prospective memory in children: Methodological issues, empirical findings, and future directions. In M. Kliegel, M. A. McDaniel, G. O. Einstein (Eds.), Prospective memory: Cognitive, neuroscience, developmental, and applied perspectives (pp. 115-140). Oxford: Taylor \& Francis.

Leigh, J., \& Marcovitch, S. (2014). The cognitive cost of event-based prospective memory in children. Journal of Experimental Child Psychology, 127, 24-35. doi:

10.1016/j.jecp.2014.02.010

Loftus, G. R., \& Masson, M. E. J. (1994). Using confidence intervals in within-subject designs. Psychonomic Bulletin \& Review, 1, 476-490. doi: 10.3758/BF03210951

Lockl, K., \& Schneider, W. (2004). The effects of incentives and instructions of children's allocation of study time. European Journal of Developmental Psychology, 1, 153-169. doi: $10.1080 / 17405620444000085$

Mahy, C. E. V., Moses, L. J., \& Kliegel, M. (2014a). The development of prospective memory in children: An executive framework. Developmental Review, 34, 305-326. doi: $10.1016 /$ j.dr.2014.08.001

Mahy, C. E. V., Moses, L. J., \& Kliegel, M. (2014b). The impact of age, ongoing task difficulty, and cue salience on preschoolers' prospective memory performance: The role of executive function. Journal of Experimental Child Psychology, 127, 52-64. doi: 10.1016/j.jecp.2014.01.006

Masur, E. F., McIntyre, C. W., \& Flavell, J. H. (1973). Developmental changes in 
apportionment of study time among items in a multitrial free recall task. Journal of Experimental Child Psychology, 15, 237-246. doi: 10.1016/0022-0965(73)90145-8

Mattli, F., Schnitzspahn, K. M., Studerus-Germann, A., Brehmer, Y., \& Zöllig, J. (2014).

Prospective memory across the lifespan: Investigating the contribution of retrospective and prospective processes. Aging, Neuropsychology, and Cognition, 21, 515-543. doi: 10.1080/13825585.2013.837860

McCauley, S. R., \& Levin, H. S. (2004). Prospective memory in pediatric traumatic brain injury: A preliminary study. Developmental Neuropsychology, 25, 5-20. doi: $10.1080 / 87565641.2004 .9651919$

McDaniel, M. A., \& Einstein, G. O. (2000). Strategic and automatic processes in prospective memory retrieval: A multiprocess framework. Applied Cognitive Psychology, 14, S127-S144. doi: 10.1002/acp.775

Neldner, K., Collier-Baker, E., \& Nielsen, M. (2015). Chimpanzees (Pan troglodytes) and human children (Homo sapiens) know when they are ignorant about the location of food. Animal Cognition, 18, 683-699. doi: 10.1007/s10071-015-0836-6

Nelson, T.O., \& Narens, L. (1990). Metamemory: A theoretical framework and new findings. Psychology of Learning and Motivation, 26, 125-173. doi: 10.1016/S00797421(08)60053-5

Redshaw, J., \& Bulley, A. (2018). Future thinking in animals: Capacities and limits. In G. Oettingen, A. T. Sevincer, \& P. M. Gollwitzer (Eds), The psychology of thinking about the future (pp. 31-51). New York: Guilford.

Redshaw, J., Henry, J. D., \& Suddendorf, T. (2016). Disentangling the effect of event-based cues on children's time-based prospective memory performance. Journal of Experimental Child Psychology, 150, 130-140. doi: 10.1016/j.jecp.2016.05.008

Redshaw, J., \& Suddendorf, T. (2016). Children's and apes' preparatory responses to two 
mutually exclusive possibilities. Current Biology, 26, 1758-1762. doi: 10.1016/j.cub.2016.04.062

Risko, E. F., \& Gilbert, S. J. (2016). Cognitive offloading. Trends in Cognitive Sciences, 20, 676-688. doi: 10.1016/j.tics.2016.07.002

Schneider, W. (2008). The development of metacognitive knowledge in children and adolescents: Major trends and implications for education. Mind, Brain, and Education, 2, 114-121. doi: 10.1111/j.1751-228X.2008.00041.x

Schneider, W., \& Löffler, E. (2016). The development of metacognitive knowledge in children and adolescents. In J. Dunlosky \& S. K. Tauber (Eds.), The Oxford handbook of metamemory (pp. 491-518). Oxford, UK: Oxford University Press.

Smith, R. E., \& Bayen, U. J. (2006). The source of adult age differences in event-based prospective memory: A multinomial modeling approach. Journal of Experimental Psychology: Learning, Memory, and Cognition, 32, 623-635. doi: 10.1037/02787393.32 .3 .623

Spiess, M. A., Meier, B., \& Roebers, C. M. (2015). Prospective memory, executive functions, and metacognition are already differentiated in young elementary school children: Evidence from latent factor modeling. Swiss Journal of Psychology, 74, 229-241. doi: $10.1024 / 1421-0185 / \mathrm{a} 000165$

Spiess, M. A., Meier, B., \& Roebers, C. M. (2016). Development and longitudinal relationships between children's executive functions, prospective memory, and metacognition. Cognitive Development, 38, 99-113. doi: 10.1016/j.cogdev.2016.02.003

Ward, H., Shum, D., McKinlay, L., Baker-Tweney, S., \& Wallace, G. (2005). Development of prospective memory: Tasks based on the prefrontal-lobe model. Child Neuropsychology, 11, 527-549. doi: 10.1080/09297040490920186 
Yang, T.-x., Chan, R. C. K., \& Shum, D. (2011). The development of prospective memory in typically developing children. Neuropsychology, 25, 342-352. doi: 10.1037/a0022239 Zimmermann, T. D., \& Meier, B. (2006). The rise and decline of prospective memory performance across the lifespan. The Quarterly Journal of Experimental Psychology, 59, 2040-2046. doi: 10.1080/17470210600917835 